\title{
Validação de metodologia analítica e estudo de estabilidade para quantificação sérica de paracetamol
}

\section{Analytical methodology validation and stability study for serum quantification of acetaminophen}

Viviane Cristina Sebben'; Rosemeri de Wallau Lugoch ${ }^{2}$; Cristina Simões Schlinker; Marcelo Dutra Arbo ${ }^{4}$; Renata Loureiro Vianna ${ }^{5}$

\author{
unitermos \\ Paracetamol \\ Quantificação sérica \\ Ultravioleta visível
}

\section{resumo}

Introdução e objetivo: Paracetamol ou acetaminofeno é atualmente um dos analgésicos-antipiréticos mais utilizados, principalmente em crianças. Porém o fácil acesso ao medicamento e o desconhecimento da população sobre seus efeitos nocivos têm aumentado muito o número de intoxicações por esse medicamento. A análise da concentração sérica de paracetamol confirma o diagnóstico. O resultado não só tem valor de certeza diagnóstica como também avalia o risco de hepatotoxicidade, indicando uso ou não do antí́doto específico $n$-acetilcisteína. $O$ objetivo deste trabalho foi propor um método analítico para quantificação sérica do paracetamol por espectrofotometria visivel em $430 \mathrm{~nm}$. Materiais e métodos: Após desproteinização da amostra, acetaminofeno ( $n$-acetil-p-aminofenol) reage com nitrito de sódio, formando 2,4-nitro-4acetaminofenol, que assume coloração amarela em meio alcalino. As figuras de mérito linearidade, precisão, exatidão, robustez, recuperação, limites de detecção e qualificç̧ão foram avaliadas segundo critérios preconizados pelo International Conference on Harmonisation (ICH) e pela Agência Nacional de Vigilância Sanitária (ANVISA). O estudo de estabilidade foi realizado após ciclos de congelamento/descongelamento, curta duração, longa duração sob refrigeração e em freezer. Resultados: O método se mostrou linear de 20 a $300 \mathrm{mg} / \mathrm{l}$. Os limites de detecção e quantificação foram de respectivamente $3,6 \mathrm{mg} / \mathrm{l}$ e $20 \mathrm{mg} / \mathrm{l}$. Conclusão: O método se mostrou preciso, exato e robusto e apresentou boa recuperação. As amostras-controle foram estáveis nas condições testadas. O método desenvolvido demonstrou possuir todos os parâmetros necessários para ser aplicado na quantificação de paracetamol em amostras de plasma ou soro humano para análise de emergência. Além disso, é uma técnica simples, de rápida execução e baixo custo. abstract

Introduction and objective: Acetaminophen or paracetamol is currently one of the most used analgesicantipyretic agents, mainly with children. However, both the easy access to this medicine and the population's unawareness of its toxic effects have contributed to a rise in the number of intoxications caused by this drug. Assessment of serum acetaminophen confirms the diagnosis. Not only does the result have diagnostic reliability but it also evaluates the risk of hepatotoxicity, indicating or not the administration of the specific antidote n-acetylcysteine. The aim of this study is to present an analytical method to the assessment of serum acetaminophen by spectrophotometric detection at $430 \mathrm{~nm}$. Materials and methods: After sample deproteinization, acetaminophen (n-acetyl-p-aminophenol) reacts with sodium nitrite forming 2.4-nitro-4acetaminophenol, which becomes yellowish in alkaline medium. For method validation, linearity, precision, accuracy, robustness, recovery and detection limits were evaluated according to ICH and ANVISA criteria. The stability study was carried out after freezing/defreezing cycles, short-time duration, long-time duration under refrigeration and long-time duration under freezing. Results: The method showed to be linear from 20 to $300 \mathrm{mg} / \mathrm{l}$. The detection and quantification limits were $3.6 \mathrm{mg} / \mathrm{l}$ and $20 \mathrm{mg} / \mathrm{l}$, respectively. Conclusion: The method was precise, accurate and robust and showed good recovery. The control-samples were stable in all tested conditions. The method developed presented all the necessary parameters to be applied in acetaminophen quantification in plasma samples or human serum for emergency analyzes. Furthermore, it is a simple, time and cost-effective technique.

\section{key words}

Acetaminophen

Serum quantification

Ultraviolet visible

1. Mestra; professora universitária; farmacêutica bioquímica do Núcleo de Análise Laboratorial do Centro de Informação Toxicológica do Rio Grande do Sul (CIT/RS) da Fundação Estadual de Produção e Pesquisa em Saúde (FEPPS) de Porto Alegre-RS.

2. Farmacêutica bioquímica do Núcleo de Análise Laboratorial do CIT/RS da FEPPS de Porto Alegre-RS.

3. Química do Núcleo de Análise Laboratorial do CIT/RS da FEPPS de Porto Alegre-RS.

4. Mestre; professor universitário; farmacêutico bioquímico do Núcleo de Análise Laboratorial do CIT/RS da FEPPS de Porto Alegre-RS.

5. Farmacêutica bioquímica do Núcleo de Análise Laboratorial do CIT/RS da FEPPS de Porto Alegre-RS. 


\section{Introdução}

Paracetamol ou acetaminofeno é um analgésico-antipirético derivado do $p$-aminofenol que possui ação antipirética alta, analgésica média e anti-inflamatória baixa ${ }^{(20)}$. Atualmente é o analgésico mais utilizado, principalmente em pediatria, substituindo o uso de salicilatos para evitar a síndrome de Reye. É um medicamento de venda livre, comercializado na forma de cápsulas, drágeas ou comprimidos de 500 a 1.000 mg cada e também de gotas ou solução, xarope, pós e pastilhas, sozinho ou em associações. Porém, esse fácil acesso ao paracetamol e o desconhecimento da população sobre seus efeitos nocivos ao organismo têm aumentado muito o número de intoxicações por esse medicamento, sendo a principal causa de intoxicação aguda em crianças ${ }^{(11)}$. Segundo os dados do Centro de Informação Toxicológica do Rio Grande do Sul (CIT/RS), entre os anos 2005 e 2008 foram atendidos mais de 24 mil casos de intoxicação humana por medicamentos, entre eles $1.661 \mathrm{com}$ paracetamol, representando em média $7 \%$ do total(14-16).

O paracetamol é bem absorvido no trato gastrintestinal, alcançando o pico plasmático após 40 a 60 minutos (30 minutos em preparações líquidas). Em casos de sobredose, a maior parte é absorvida em 2 horas, mas o pico plasmático não é atingido antes de 4 horas. A biodisponibilidade é alta (cerca de $60 \%$ a 95\%) e o volume de distribuição é de 0,8 a $1 \mathrm{l} / \mathrm{kg}$. A ligação a proteínas é de $10 \%$ a $30 \%$, podendo chegar a $50 \%$ em casos de sobredose. Atravessa a barreira placentária e hematoencefálica. O leite contém menos de $2 \%$ da dose materna ${ }^{(11)}$. A principal via de biotransformação (mais de $90 \%$ da quantidade absorvida) é a hepática, que ocorre por meio de três mecanismos metabólicos: conjugação com ácido glicurônico ( $40 \%$ a $67 \%$ ), sulfatação (20\% a $46 \%$, principalmente em crianças) e oxidação (5\% a 15\%). Enquanto conjugação e sulfatação são processos saturáveis e que produzem metabólitos atóxicos que são eliminados pela urina, a via oxidativa produz um metabólito reativo altamente tóxico que, em condições terapêuticas, se une a glutationa, formando conjugados de cisteína e ácido mercaptúrico. Em sobredosagem, após saturação das vias metabólicas principais, maior quantidade de paracetamol sofre oxidação, gerando maior quantidade de metabólito tóxico ( $n$-acetil-p-benzoquinonimina [NAPBQI]), excedendo a capacidade de desintoxicação da glutationa. O tempo de meia-vida é de 1 a 3 horas e em sobredose pode chegar a 12 horas. Doses de 150 e $200 \mathrm{mg} / \mathrm{kg}$, respectivamente, em adultos e crianças são passíveis de causar danos hepáticos ${ }^{(1,9,11,17)}$.

Quando as reservas de glutationa chegam a menos de $30 \%$, o NAPBQI livre exerce sua ação tóxica sobre os hepa- tócitos, ligando-se covalentemente a proteínas intracelulares, podendo levar à morte celular. Além desse mecanismo oxidativo, outras vias fisiopatológicas complementares têm sido propostas experimentalmente, como formação de radicais livres, perturbação da homeostase do cálcio, inibição da cadeia respiratória mitocondrial etc. ${ }^{(11)}$.

O quadro clínico de intoxicação por paracetamol apresenta geralmente três períodos bem definidos, podendo chegar a um quarto, resolutivo. Nas primeiras 24 horas 0 paciente se apresenta assintomático ou com leve mal-estar, náuseas, vômitos, palidez e epigastralgia. Entre 24 e 72 horas o paciente pode seguir clinicamente assintomático ou apresentar sintomatologia leve, semelhante ao primeiro período e/ou iniciar com dor no hipocôndrio direito. Sua alteração característica é o aumento das transaminases hepáticas. $\mathrm{O}$ período de 72 horas a cinco dias é de máxima expressão da hepatotoxicidade, podendo evoluir para falência hepática aguda. Os sintomas clínicos podem variar de pouco expressivos até quadro de encefalopatia, coma e transtornos de coagulação, dependendo do grau de disfunção hepática. São observadas elevação extrema de transaminases, bilirrubina total e tempo de protrombina. Se a insuficiência hepática aguda não levar a óbito, a reversibilidade é total, estando o tecido hepático regenerado por completo entre cinco e sete

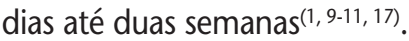

A análise da concentração sérica de paracetamol confirma o diagnóstico. O resultado não só tem valor de certeza diagnóstica como também avalia o risco de hepatotoxicidade, indicando uso do antídoto específico ( $n$-acetilcisteína). Para isso utiliza-se o nomograma de Rumack-Matthew ${ }^{(2)}$ (Figura), que indica se o antídoto deve ser administrado segundo concentração plasmática de paracetamol relacionada com o intervalo transcorrido desde a ingesta do medicamento até a coleta do sangue ${ }^{(11)}$. Uma opção de metodologia de análise para serviço de emergência, em que devem ser considerados fatores como baixo custo operacional, simplicidade e rapidez de execução, é a espectrofotometria visível, que é apresentada neste trabalho como um método analítico para a quantificação sérica do paracetamol.

\section{Materiais e métodos}

\section{Fundamento do método}

Após desproteinização da amostra, acetaminofeno ( $n$-acetil-p-aminofenol) reage com nitrito de sódio, formando 2,4-nitro-4-acetaminofenol, que assume coloração amarela em 


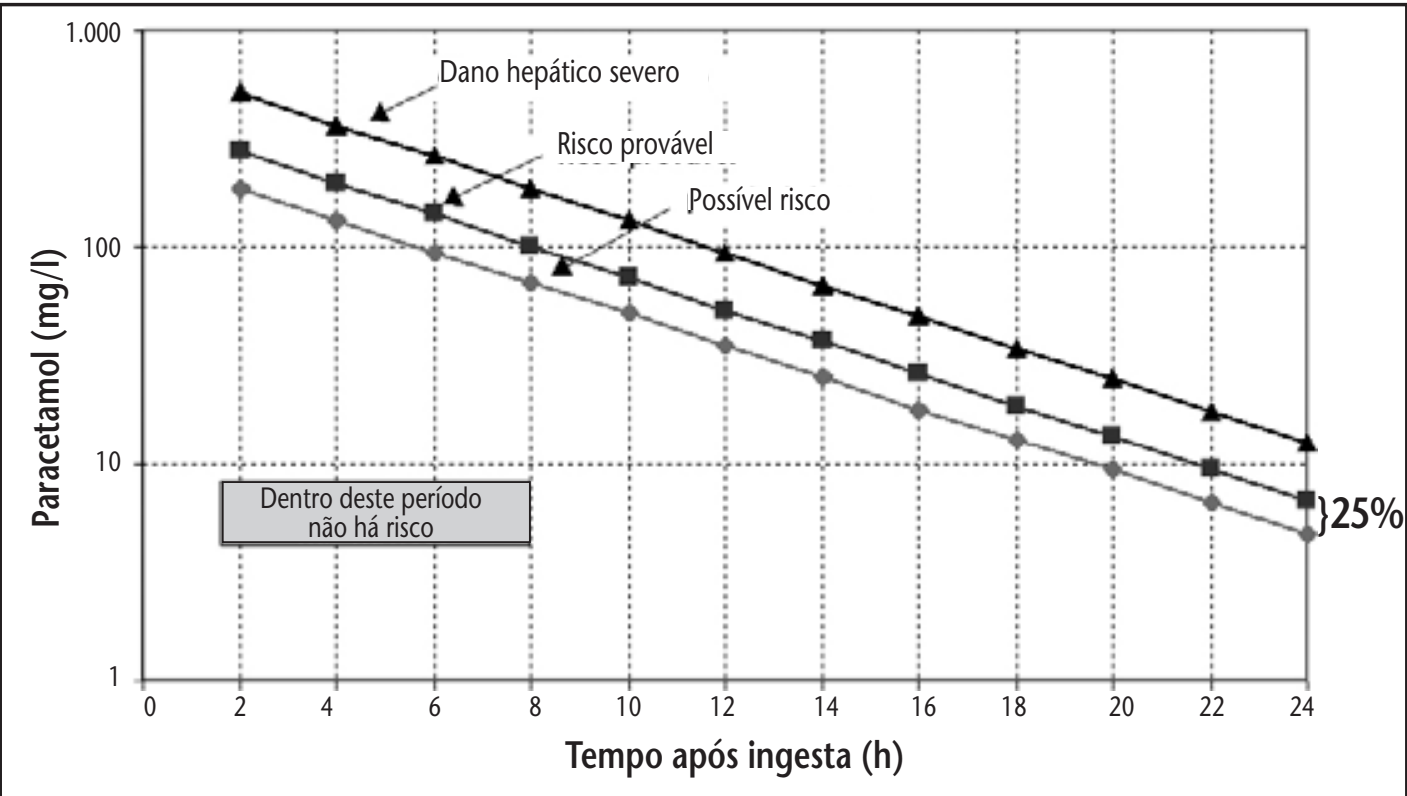

Figura - Nomograma de Rumack-Matthew. É utilizado para indicar a administração do antídoto n-acetilcisteína segundo a concentração plasmática de paracetamol relacionada com o intervalo transcorrido desde a ingesta do medicamento até a coleta do sangue

Fonte: Nomograma adaptado da American Academy on Pediatrics (2001).

meio alcalino. A intensidade dessa coloração é proporcional à concentração do acetaminofeno, que pode ser quantificado em espectrofotômetro no comprimento de onda de $430 \mathrm{~nm}^{(5)}$.

\section{Amostras e controles biológicos}

O material biológico mais adequado para detecção de acetaminofeno é o soro. A análise toxicológica só tem valor diagnóstico e prognóstico se realizada entre 4 e 24 horas após a ingesta. Antes de 4 horas, ela continua tendo valor para diagnóstico, mas não para prognóstico, uma vez que a absorção não é completa. Entretanto, transcorridas 24 horas, o paracetamol será totalmente metabolizado, tornando-se indetectável e não tendo valor diagnóstico ${ }^{(11)}$.

A solução estoque padrão (SP) foi obtida pesando cerca de $50 \mathrm{mg}$ de acetaminofeno, que foram transferidos para balão volumétrico de $50 \mathrm{ml}$ e solubilizados com água purificada, obtendo-se uma SP de $1 \mathrm{mg} / \mathrm{ml}$. Diluições apropriadas da SP foram efetuadas com plasma isento de acetaminofeno para execução do gráfico de calibração nas concentrações de 20, 50, 100, 150, 200, 250 e 300 mg/l. Já para estudo de validação foram utilizados plasmas controle de acetaminofeno nas concentrações de 50, 100 e 200 mg/l.

\section{Reagentes e equipamentos}

Acetaminofeno (99\%) foi adquirido da Sigma (St. Louis, EUA), ácido tricloroacético (TCA) (99\%) da Vetec (Rio de
Janeiro, Brasil), hidróxido de sódio (98\%) do Conselho Regional de Química (CRQ) (São Paulo, Brasil) e nitrito de sódio (99\%) da Carlo Erba (Rodano, Itália). As amostras biológicas de plasma foram cedidas pelo Hemocentro de Porto Alegre-RS (HEMORGS).

O equipamento utilizado foi espectrofotômetro UV-VIS CARY ${ }^{\circledR} 1 \mathrm{E}$ da Varian (Mulgrave, Austrália), comprimento de onda $430 \mathrm{~nm}$, utilizando células de poliestireno de $10 \mathrm{~mm}$ de caminho óptico.

\section{Procedimento analítico}

Em tubos de ensaio cônicos (tipo Falcon) foram adicionados $500 \mu \mathrm{l}$ de amostra, que foi desproteinizada pela adição de $5 \mathrm{ml}$ de TCA 3\%, seguido de agitação em mixer por 30 segundos. Após sua centrifugação por 10 minutos a $5.000 \mathrm{~g}, 2 \mathrm{ml}$ do sobrenadante foram pipetados para outro tubo de ensaio, no qual foram adicionados $0,5 \mathrm{ml}$ de nitrito de sódio $0,07 \mathrm{M}$, recém-preparados e agitados em mixer por 5 segundos. Após 10 minutos de banho-maria a $37 \pm 1{ }^{\circ} \mathrm{C}$, foram adicionados $100 \mu \mathrm{l}$ de $\mathrm{NaOH} 8 \mathrm{M}$ para o aparecimento da coloração amarela. Após agitação em mixer por 30 segundos, as absorbâncias das amostras foram lidas em espectrofotômetro a $430 \mathrm{~nm}$.

\section{Validação}

As figuras de mérito linearidade, precisão, exatidão, robustez, recuperação, limites de detecção (LD) e de 
quantificação (LQ) foram avaliadas segundo os critérios preconizados pela ANVISA(4) e pelo ICH(6).

\section{Estabilidade}

Para os testes de estabilidade utilizaram-se controles com concentrações baixa $(64 \mathrm{mg} / \mathrm{l})$, média $(116 \mathrm{mg} / \mathrm{l})$ e alta $(205 \mathrm{mg} / \mathrm{l})$ do analito em questão e em triplicata, preparados a partir de solução padrão $1 \mathrm{mg} / \mathrm{ml}$ de acetaminofeno, adicionado à matriz biológica (plasma) isenta de interferência. Antes do início do estudo de estabilidade, os controles foram analisados pelo método analítico e validados, obtendo-se as concentrações no tempo zero, que foram comparadas com aquelas conseguidas após diferentes condições de armazenamento.

As circunstâncias de realização dos ensaios de estabilidade reproduziram as reais condições de manuseio e análise das amostras ${ }^{(18)}$ :

- após ciclos de congelamento e descongelamento: os controles foram armazenados em freezer a $-18^{\circ} \mathrm{C}$ por 24 horas, sendo então submetidos a descongelamento a $37^{\circ} \mathrm{C}$. Quando completamente descongelados, repetiu-se o procedimento anterior até completar três ciclos;

- curta duração: os controles foram mantidos a temperatura ambiente (entre 20 e $25^{\circ} \mathrm{C}$ ) por 6 , 24, 48 e 72 horas;

- longa duração sob refrigeração: os controles foram armazenados entre 2 e $8^{\circ} \mathrm{C}$ por 5, 15 e 30 dias;

- longa duração em freezer: os controles foram armazenados a $-18^{\circ} \mathrm{C}$ por $5,30,90,180,270$ e 360 dias.

\section{Resultados e discussão}

\section{Validação do método analítico}

\section{Linearidade}

Corresponde à capacidade do método de fornecer resultados diretamente proporcionais à concentração da substância em análise ${ }^{(4,6)}$ e foi estabelecida pela média de três curvas padrão, que foram obtidas em sete níveis de concentrações diferentes de paracetamol (20, 50, 100, 150, 200, 250 e $300 \mathrm{mg} / \mathrm{ll}$. Cada concentração foi determinada em triplicata para cada curva padrão. A linearidade foi avaliada por meio de análise de regressão linear, utilizando ajuste dos dados pelo método dos mínimos quadrados, cuja equação da reta é dada por Absorbância = 0,00154 $\times$ Paracetamol $(\mathrm{mg} / \mathrm{l})$, e o coeficiente de correlação foi de 0,99911, estando de acordo com o recomendado pela ANVISA ${ }^{(4)}$ e pelo $\mathrm{ICH}^{(6)}$ de no mínimo 0,98 . Portanto, o método analítico desenvolvido possui faixa de linearidade entre as concentrações de paracetamol de 20 e $300 \mathrm{mg} / \mathrm{l}$.

Limites de detecção (LD) e quantificação (LQ)

LD é a menor concentração do analito que o procedimento analítico consegue diferenciar. Foi estabelecido que ele é três vezes superior ao desvio padrão de uma série de medidas de branco (plasma isento de paracetamol)(4, 6). A partir da análise de uma amostra de branco, o LD encontrado foi de 3,6 mg/l.

LQ é a menor quantidade de analito na amostra que pode ser determinada com precisão e exatidão( ${ }^{(4,6)}$. Foi estabelecido que ele é de $20 \mathrm{mg} / \mathrm{l}$.

\section{Precisão e exatidão}

A precisão do método fornece a dispersão dos valores medidos em torno de um valor médio ${ }^{(13)} \mathrm{e}$ foi calculada como coeficiente de variação (CV\%) de três concentrações, realizando cinco determinações por concentração em um único dia (repetibilidade) e em três dias diferentes (precisão intermediária), não sendo admitidos valores superiores a $15 \%(4,6)$. Os resultados estão descritos na Tabela.

A exatidão do método reflete a proximidade entre o valor medido e um valor de referência considerado como

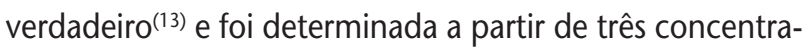
ções, realizando cinco determinações por concentração em um único dia e em três dias diferentes, não sendo admitidos valores superiores a $15 \%$. Os resultados estão descritos na Tabela e demonstram que o método analítico proposto é preciso e exato.

\section{Robustez}

Mede a sensibilidade que um método apresenta frente a pequenas variações ${ }^{(4,6)}$. Alterações de parâmetros analíticos, como temperatura, $\mathrm{pH}$ da amostra, tempo de agitação no mixer, fabricante dos solventes e operador, não influenciaram significativamente o resultado das análises.

\section{Recuperação}

É definida como a proporção da quantidade de substância de interesse que é extraída e passível de ser quantificada. Foi avaliada por comparação com amostras de plasma contendo padrão de acetaminofeno em água não extraídas em três diferentes concentrações (50, 100 e 200 mg/ml), 
Tabela Resultados dos estudos de exatidão, precisão e recuperação do método analítico

\begin{tabular}{cccccc}
\hline $\begin{array}{c}\text { Concentração } \\
(\mathrm{mg} / \mathrm{l})\end{array}$ & $\begin{array}{c}\text { Exatidão } \\
(\%)\end{array}$ & $\begin{array}{c}\text { Exatidão } \\
(\mathrm{CV} \%)\end{array}$ & $\begin{array}{c}\text { Precisão intermediária } \\
(\text { CV\%) }\end{array}$ & $\begin{array}{c}\text { Repetibilidade } \\
\text { (CV\%) }\end{array}$ & $\begin{array}{c}\text { Recuperação } \\
(\%)\end{array}$ \\
50 & 92 & 8 & 1,6 & 1,34 & 108,4 \\
100 & 95 & 5 & 1 & 1,92 & 105,5 \\
200 & 96,5 & 3,5 & 1,1 & 2,1 & 102,5 \\
\hline
\end{tabular}

CV: coeficiente de variação.

contemplando a faixa de linearidade do método. É importante considerar como a eficiência do método varia em função da concentração da substância, podendo interferir na recuperação em baixas e altas concentrações. Os valores obtidos estão descritos na Tabela. Já os valores aceitáveis de recuperação estão, em geral, entre 70 e $120 \%(4,6,8,12)$.

\section{Interferentes}

Drogas como cafeína, cefalexina, cloromicetina, diflunisal, etosuximida, $n$-acetilcisteína, neomicina, oxifembutazona, fenobarbital, fenilbutazona, ácido salicílico, sulfanilamida, sulfixosazol e teofilina, na concentração de $100 \mathrm{mg} / \mathrm{l}$, podem levar a aparente valor de paracetamol entre 0 e 20 mg/l. Essa interferência não tem importância clínica significativa, a menos que a amostra venha a ser obtida após 10 a 12 horas da ingesta.

$\mathrm{O}$ ácido $p$-aminossalicílico também interfere, resultando valores aparentes de paracetamol na ordem de $32 \mathrm{mg} / \mathrm{l}$.

A $n$-acetilcisteína, antídoto utilizado no tratamento da intoxicação, produz uma coloração laranja fraca após a adição do nitrito de sódio. A interferência não é significativa, pois o incremento no valor de acetaminofeno é inferior a $1 \mathrm{mg} / \mathrm{l}^{(5)}$.

Os níveis séricos de acetaminofeno, quando analisados pelo método colorimétrico, podem não ser confiáveis na presença de bilirrubina elevada, dano renal ou salicismo ${ }^{(3,7)}$. Nesses casos, recomenda-se a dosagem por cromatografia líquida de alta performance (CLAE) ou imunoensaio enzimático.

\section{Estabilidade}

As amostras de plasma com paracetamol foram consideradas estáveis quando não se observaram desvios superiores a $20 \%$ do valor obtido no tempo zero para concentração baixa e superiores a 15\% para concentrações média e alta. As amostras se apresentaram estáveis em todas as condições testadas.

\section{Interpretação dos resultados}

O resultado da dosagem de acetaminofeno $(\mathrm{mg} / \mathrm{l})$ deve ser analisado frente ao nomograma de Rumack-Matthew (2), considerando a correlação entre concentração de acetaminofeno e tempo decorrido entre a ingesta e a coleta do sangue (Figura).

\section{Conclusão}

Os métodos analíticos para detecção e quantificação de fármacos em amostras biológicas são um importante instrumento para diagnóstico de intoxicações. Por isso, a importância de contar com métodos bem caracterizados, validados e, portanto, confiáveis ${ }^{(21)}$. Apesar das vantagens indiscutíveis na sua utilização, as técnicas cromatográficas, como CLAE e cromatografia a gás (CG), apresentam algumas limitações, como alto custo de instrumentação e operação, tempo relativamente longo de análise e necessidade de experiência no manuseio do equipamento e no tratamento de amostras ${ }^{(19)}$.

O método desenvolvido neste trabalho mostrou possuir todos os parâmetros necessários para ser aplicado na quantificação de paracetamol em amostras de plasma ou soro humano para análise de emergência, sendo linear, preciso, exato e robusto. Além disso, é uma técnica simples, de rápida execução e baixo custo, requisitos importantes para um serviço público de emergência. 


\section{Referências}

1. AMERICAN ACADEMY OF PEDIATRICS. Acetaminophen toxicity in children. Pediatrics, v. 108, n. 4, p. 1020-24, 2001.

2. AMERICAN ACADEMY OF PEDIATRICS. Committee on Injury and Poison Prevention. Handbook of Common Poisonings in Children. AAP, Elk Grove Village, 1994.

3. BERTHOLF, R. L. et al. False-positive acetaminophen results in a hyperbilirubinemic patient. Clin Chem, v. 49, p. 695-8, 2003.

4. BRASIL. AGÊNCIA NACIONAL DE VIGILÂNCIA SANITÁRIA. Resolução n. 899, de 29 de maio de 2003. Diário Oficial da República Federativa do Brasil, Brasília, DF. Determina a publicação do guia para validação de métodos analíticos e bioanalíticos por meio da revogação da RE n. 475 publicada no DOU em 19 de março de 2002.

5. HALE, P. W.; POKLIS, A. Evaluation of a modified colorimetric assay for the determination of acetaminophen in serum. J Anal Toxicol, v. 7, p. 249-51, 1983.

6. INTERNATIONAL CONFERENCE HARMONIZATION $(\mathrm{ICH})$. Validation of analytical procedures: text and methodology, 2005.

7. JENNY, R. W. Interlaboratory evaluation of salicylate interference in colorimetric acetaminophen methods and its clinical significance. Clin Chem, v. 31, p. 1158-62, 1985.

8. MARTINS, I. Validação analítica. In: MOREAU, R. L. M.; SIQUEIRA, M. E. P. B. Toxicologia analítica. Rio de Janeiro: Guanabara Koogan, 2008.

9. MOKHLESI, B. et al. Adult toxicity in critical care. Part II: specific poisonings. Chest, v. 123, p. 897-922, 2003.

10. MOTA, A. H. et al. Intoxicações medicamentosas análise toxicológica com apoio ao diagnóstico. Acta Médica, v. 27, p. 473-80, 2006.

11. MUNNÉ, P. et al. Intoxicaciones medicamentosas (II). Analgésicos y anticonvulsivantes. Anais do Sistema Sanitário de Navarra, Espanha, v. 26, p. 65-97, 2003.

12. RIBANI, M. et al. Validação em métodos cromatográficos e eletroforéticos. Quim Nova, v. 27, p. 771-80, 2004.
13. RIBEIRO, F. A. L. et al. Planilha de validação: uma nova ferramenta para estimar figuras de mérito na validação de métodos analíticos univariados. Quim Nova, v. 31, p. 164-71, 2008.

14. RIO GRANDE DO SUL. SECRETARIA DA SAÚDE. FUNDAÇÃO ESTADUAL DE PRODUÇÃO E PESQUISA EM SAÚDE. CENTRO DE INFORMAÇÃO TOXICOLÓGICA. Toxicovigilância. Toxicologia clínica: dados e indicadores selecionados, Rio Grande do Sul 2005. Porto Alegre: CIT/RS, 2006. 99p.

15. RIO GRANDE DO SUL. SECRETARIA DA SAÚDE. FUNDAÇÃO ESTADUAL DE PRODUÇÃO E PESQUISA EM SAÚDE. CENTRO DE INFORMAÇÃO TOXICOLÓGICA. Toxicovigilância. Toxicologia clínica: dados e indicadores selecionados, Rio Grande do Sul 2006. Porto Alegre: CIT/RS, 2007. 100p.

16. RIO GRANDE DO SUL. SECRETARIA DA SAÚDE. FUNDAÇÃO ESTADUAL DE PRODUÇÃO E PESQUISA EM SAÚDE. CENTRO DE INFORMAÇÃO TOXICOLÓGICA. Toxicovigilância. Toxicologia clínica: dados e indicadores selecionados, Rio Grande do Sul 2007. Porto Alegre: CIT/RS, 2008. 99p.

17. ROWDEN, A. K. et al. Updates on acetaminophen toxicity. Med Clin N Am, v. 89, p. 1145-59, 2005.

18. SEBBEN, V. C. et al. Estabilidade dos metabólitos da cocaína, maconha e anfetaminas em urina por EMIT. Química Hoje, n. 7, p. 9-11, 2007.

19. SIQUEIRA-MOURA, M. P.; LIRA, M. C. B.; SANTOSMAGALHÃES, N. S. Validação de método analítico espectrofotométrico UV para determinação de ácido úsnico em lipossomas. RBCF, v. 44, p. 621-8, 2008.

20. TAGLIATI, C. A. Antiinflamatórios. In: OGA, S.; CAMARGO, M. M. A.; BATISTUZZO, J. A. O. Fundamentos de toxicologia. São Paulo: Atheneu, 2008.

21. VOLONTÉ, M. G. et al. Desarrollo y validación de un método por HPLC para la determinación de carbamacepina en plasma humano. Lat Am J Pharm, v. 28, p. $80-5,2009$.

\begin{tabular}{l|l} 
& \\
& Endereço para correspondência \\
\hline & Viviane C. Sebben \\
Centro de Informação Toxicológica & \\
do Rio Grande do Sul \\
Núcleo de Análise Laboratorial \\
Rua Domingos Crescêncio, 132/70 andar \\
Porto Alegre-RS \\
CEP: 90650-090
\end{tabular}

